\title{
Journal of Veterinary Science \& Technology
}

\section{A Typical Case of True Schistosomus Reflexus (SR) in a Local Ewe of Kashmir} Mehraj-U-Din Dar, Firdous Ahmad, Khadim Hussain Dar ${ }^{*}$ and Hakim Athar

Division of Veterinary Surgery and Radiology, Veterinary Sciences \& Animal Husbandry, Sher-e Kashmir University of Agricultural Sciences and Technology, Kashmir-190006, India

*Corresponding author: Khadim Hussain Dar, Division of Veterinary Surgery and Radiology, Veterinary Sciences \& Animal Husbandry, Sher-e Kashmir University of Agricultural Sciences and Technology, Kashmir-190006, India, Tel: 0194246 2758; E-mail: drkhadim23@gmail.com

Rec date: Jun 13, 2015; Acc date: Jul 25, 2015; Pub date: Jul 27, 2015

Copyright: @ 2015 Dar MUD, et al. This is an open-access article distributed under the terms of the Creative Commons Attribution License, which permits unrestricted use, distribution, and reproduction in any medium, provided the original author and source are credited.

\begin{abstract}
An adult ewe weighing $34.65 \mathrm{~kg}$ at full term of pregnancy as per the owner was presented with the history of straining and unable to undergo the normal physiological process of lambing. Vaginal examination revealed a deformed fetus in the pelvic cavity that left insufficient room for fetal manipulation. The dystocia was relieved by caesarean section and a case of true Schistosomus reflexus (SR) in a ewe was confirmed from physical examination of the defective fetus. The ewe was under observation for four weeks. The ewe was found active on 25 days post-surgery with gain of extra $3 \mathrm{~kg}$ bodyweight.
\end{abstract}

Keywords: Ewe; Sheep; Schistosomus reflexus

\section{Introduction}

Schistosomus reflexus (SR) is a rare type of fetal monster primarily seen in cattle and rare in small ruminants especially in ewes [1]. This fatal congenital syndrome is characterized by the presence of exposed abdominal and sometimes thoracic viscera (Schistosomus) and marked spinal inversion producing a distinctive ventral convex curvature [2]. These abnormalities suggest SR occurs as early as the post-gastrulation embryo and involves the intermediate mesoderm [3]. However only the cases that display both visceral exposure and spinal inversion are considered as true schistosomus reflexus [4]. Due to the wedging of the fetus in the pelvis and the narrow vaginal passage of the ewe, the monster lambs are usually relieved by cesarean section [5]. The paper reports a case of true schistosomus reflexus in ewe that was encountered in the Division of Surgery and Radiology, F.V.Sc \& A.H, SKUAST-Kashmir.

\section{History and Clinical Observation}

An adult ewe weighing $34.65 \mathrm{~kg}$ her second lambing at full term of pregnancy as per the owner was presented with the history of straining and unable to undergo the normal physiological process of lambing. Upon clinical examination the ewe was found to be active and in good condition. Respiratory rate and heart rate were within normal physiological range. However rectal temperature although slightly raised $\left(39.6^{\circ} \mathrm{C}\right)$ but was within normal range for ewe. The visible conjunctival mucous membranes were pink. On closer visual examination congested intestinal loops were seen protruding from the vagina which upon digital vaginal examination was confirmed to be that of fetus. On vaginal examination the fetal head was palpated in the cervix. Therefore a tentative diagnosis of dystocia due to fetal deformity was made. Attempts to manipulate the fetus and relieve the dystocia by traction were not fruitful due to insufficient room in the pelvic cavity. Thus cesarean section was planned.

\section{Management and Treatment}

The ewe was administered ceftriaxone @10 mg/kg, intramuscularly (IM) and meloxicam @0.5 mg/kg intravenously (IV) 30 minutes prior to premedication Then ewe was administered diazepam hydrochloride slowly@ $0.5 \mathrm{mg} / \mathrm{kg}$ body weight intravenously and IV fluid line (5\% DNS) was established. The ewe was restrained in left lateral recumbency on soft bedding. The protruded fetal mass hanging from the vulva mass was covered with a sterile moist towel and the right para-median area was prepared for aseptic surgery. Local anesthesia was achieved by infiltrating 2\% lignocaine $\mathrm{HCl} @ 4.5 \mathrm{mg} / \mathrm{kg}$ (Lignocaine and Adrenaline injection, Intas Pharmaceuticals Ltd, India) using the linear infiltration. After the anaesthesia $7 \mathrm{~cm}$ long incision was made through the abdominal wall and into the peritoneal cavity. After exposing the uterus and uterine horns, a longitudinal incision was made on the dorsal curvature of the right uterine horn through which the fetus was extracted along with the hanging intestinal loops which protruded through the vagina (Figure 1). The uterine incision was sutured with No. 1 chromic catgut in two layers using continuous cushing and lamberts pattern respectively. Abdominal muscles were opposed using No. 2 chromic catgut in a continuous pattern. The skin was closed using braided silk No.1 in a horizontal mattress pattern (Figure 2).

Postoperatively, ceftriaxone (0.5 g, BID, IM) and meloxicam $(0.5$ $\mathrm{mg} / \mathrm{kg}, \mathrm{OD}, \mathrm{IM})$ were prescribed for five and three days respectively. Antiseptic dressing using 5\% povidone iodine was continued twice daily till suture removal on 12 days post- operation. The animal was found active and alert 25 days post-operation with $3 \mathrm{~kg}$ extra body weight gain.

\section{Fetal Description}

The removed fetus was malformed with marked ventral curvature of spine (Figure 3), lateral bending of fetal body and chest wall exposing abdominal viscera with deformed pelvis and ankylosis of limbs (Figure 1) and was diagnosed to be a case of true schistosomus reflexus (Figure 4). 
Citation: Dar MUD, Ahmad F, Dar KH, Athar H (2015) A Typical Case of True Schistosomus Reflexus (SR) in a Local Ewe of Kashmir. J Veterinar Sci Technol 6: 241. doi:10.4172/2157-7579.1000241

Page 2 of 2

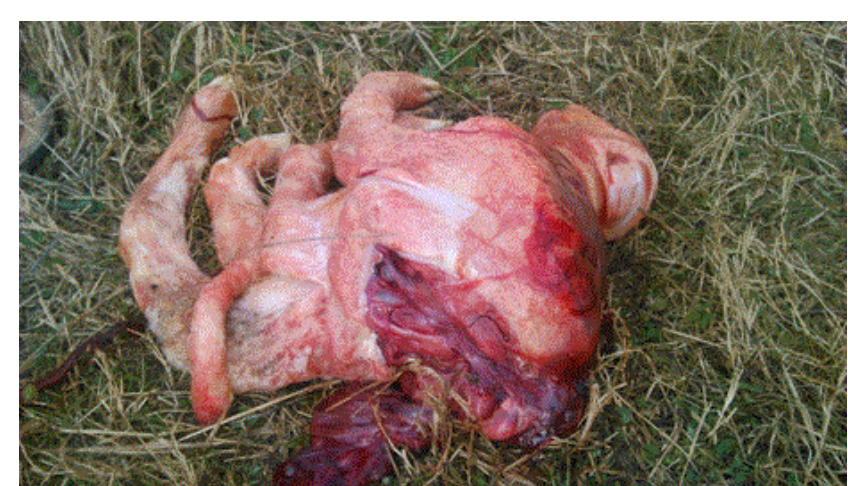

Figure 1: A case of schistosomus reflexus in a lamb showing exposed abdominal and thoracic viscera.

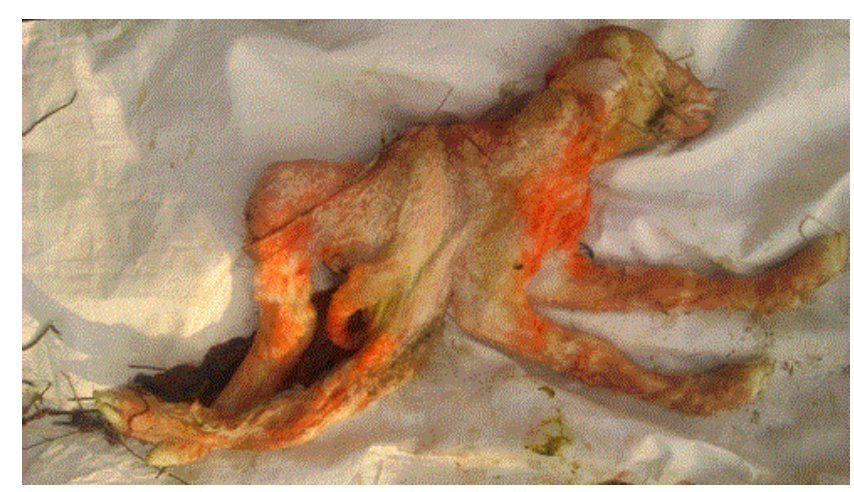

Figure 2: Right lateral view with malformed fetus having extended limbs.

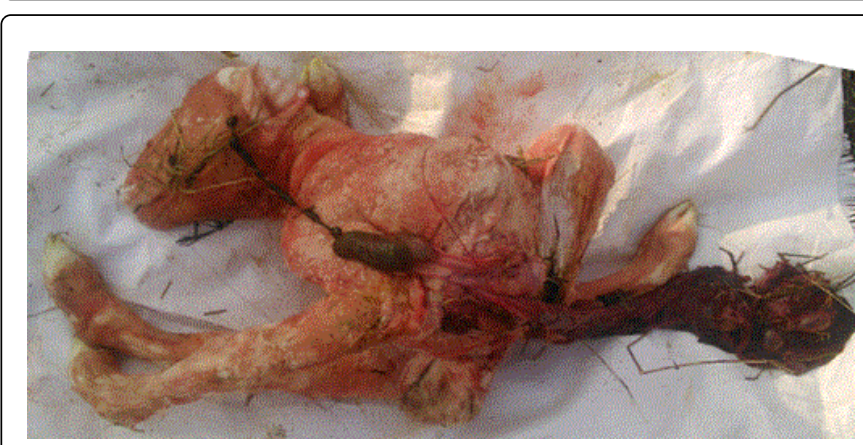

Figure 3: Left lateral view with exposed viscera and marked spinal curvature.

\section{Discussion}

Schistosomus reflexus (SR) is a common fatal congenital disorder, primarily observed in ruminants [6]. The defining features include spinal inversion either dorsi-flexion or retro-flexion of vertebral column with or without ankylosis, joint contractures or limbs ankylosis and exposure of abdominal and or thoracic viscera owing to severe form of abdominal herniation or fissures on ventral or midventral abdominal wall which were similar to findings of the present case [5,7].

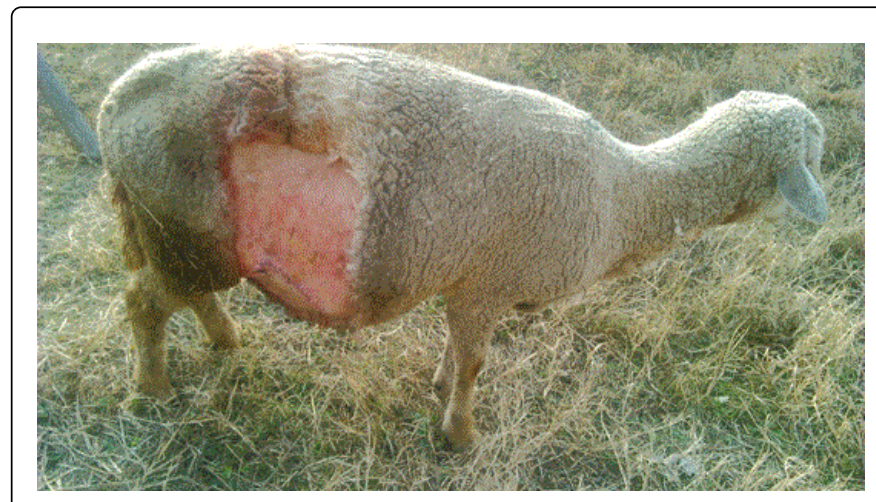

Figure 4: The ewe standing immediately after the surgical intervention.

The definitive aetiology of SR remains unclear [2] however chromosomal involvement and exposure to teratogenic agents have been the likely causes of schistomus reflexus [8]. Majority of congenital anomalies are reported to be related to genetic factors, mutations, chromosomal anomalies, infectious agents, and environmental factors or the combination of all the factors listed [6]. Removed fetus that displays both visceral exposure and spinal inversion is considered as a true case of SR [4] same was as found in the present case.

\section{Acknowledgement}

The authors are highly thankful to Dr. B.A. Moulvi, Professor and Head, Division of Veterinary Surgery and Radiology F.V.Sc \& A.H, SKUAST-K, for his persistent, valuable guidance and close supervision.

\section{References}

1. Dennis SM (1972) Schistosomus reflexus in conjoined twin lambs. Vet Rec 90: 509-510.

2. Robetrs SJ (1998) Veterinary Obstetrics and Genital Diseases (Theriogenology) (2ndedn) New Delhi, CBS Publishers and Distributors. pp. 180-183.

3. Mukasa-Mugerwa E, Bekele $T$ (1989) Schistosomus reflexus in indigenous Ethiopian sheep. Bulletin of Ani Healt Prod in Africa pp. 337-399.

4. Laughton KW, Fisher KR, Halina WG, Partlow GD (2005) Schistosomus reflexus syndrome: a heritable defect in ruminants. Anat Histol Embryol 34: 312-318.

5. Ozcan K, Öztürkler Y, Tuzcu M, Erginsoy S (2003) Schistosomus reflexus in cattle in Kars province. Indian Vet J 80:693-694.

6. Tsuma VT, Abuom TO (2008) A case report of Schistosomus Reflexus in a Lamb. The Kenya Veterinarian 32:41-43.

7. Cavalieri J, Farin PW (1999) Birth of a Holstein freemartin calf cotwinned to a schistosomus reflexus fetus. Theriogenology 52: 815-826.

8. Magaji AA, Umaru MA, Obudu CE, Agaie BM, Sonfada ML (1999) A case report of Schistosomus reflexus in a maradi Goat. Sokoto Journal of Vet Sci 1:79-82. 